\title{
Relapse Rate and Factors Related to Relapse in a 1-Year Follow-Up of Subjects Participating in a Smoking Cessation Program
}

\author{
Nagihan Durmuş Koçak MD, Ayşegül Eren MD, Sibel Boğa MD, Ülkü Aka Aktürk MD, \\ Ülkem Angın Öztürk MD, Sibel Arınç MD, and Aysun Şengül MD
}

\begin{abstract}
BACKGROUND: The most important and difficult task when it comes to reducing tobacco-related morbidity and mortality is to convince smokers to quit and to maintain their abstinence. This study aimed to determine the smoking relapse rate and factors related to relapse in subjects who participated in a smoking cessation program and completed a 1-y follow-up in our center. METHODS: The study included 550 subjects who applied to a smoking cessation clinic from June 1, 2011 to December 31, 2011 and completed the 1-y follow-up. RESULTS: After 1 y, 282 (51.4\%) subjects had relapsed, $132(24 \%)$ had quit smoking, and $135(24.6 \%)$ could not be contacted. The mean age \pm SD was $41.5 \pm 10.8 \mathrm{y}$, and $52.5 \%$ were male. There was no difference between non-relapsed and relapsed subjects with regard to age, sex, average smoking duration and daily number of cigarettes, reason to quit, education level, presence of symptoms and concomitant diseases, Fagerström nicotine dependence score, Beck depression score, and frequency of pharmacotherapy administration. In the relapsed group, the age began smoking was younger $(P=.05)$, and the longest prior duration of abstinence was shorter $(P=.04)$. The average number of support contacts was found to be significantly higher in the non-relapsed subjects $(P<.001)$. Logistic regression analysis revealed alcohol intake to be a factor influencing relapse (odds ratio: $2.11,95 \%$ CI: $1.13-3.93, P=.02$ ), as was the number of support contacts (odds ratio: $2.06,95 \%$ CI: $1.59-2.65, P<.001$ ). The presence of drug adverse effects was close to being significant (odds ratio: 1.96, 95\% CI: 0.93-4.10, $P=.07$ ). CONCLUSION: The relapse rate in a $1-y$ period was $51.4 \%$. Similar to previous studies, alcohol intake presented a relapse risk. In subjects receiving drug treatment, planning support meetings more frequently and paying attention to adverse effects may increase the success of smoking cessation. Key words: smoking; smoking cessation; alcohol dependence; varenicline; bupropion; nicotine replacement products; drug-related adverse reactions. [Respir Care 2015;60(12):1796-1803. (C) 2015 Daedalus Enterprises]
\end{abstract}

\section{Introduction}

Despite increased awareness of the risks of smoking, it continues to present a serious public health problem and constitutes one of the most frequent, preventable cause of

\footnotetext{
Drs Koçak, Eren, Boğa, Aktürk, and Arınç are affiliated with the Department of Pulmonary Diseases, Süreyyapaşa Chest Diseases and Thoracic Surgery Education and Research Hospital, Istanbul, Turkey. Dr Öztürk is affiliated with the Department of Psychiatric Diseases, Süreyyapaşa Chest Diseases and Thoracic Surgery Education and Research Hospital, Istanbul, Turkey. Dr Şengül is affiliated with the Department of Pulmonary Diseases, Kocaeli Derince Education and Research Hospital, Kocaeli, Turkey.
}

morbidity and mortality. ${ }^{1-3}$ According to World Health Organization estimates, one-third of the world's popula-

\begin{abstract}
This study was presented as an oral presentation at the 35th Annual Congress of TÜSAD Solunum 2013, held October 2-6, 2013, in Çeşmeİzmir, Turkey.
\end{abstract}

The authors have disclosed no conflicts of interest.

Correspondence: Nagihan Durmuş Koçak MD, Süreyyapasa Göğüs Hastalıkları ve Göğüs Cerrahisi Eğitim ve Araştırma Hastanesi, C blok 2. Kat, Başıüyü̈k-Maltepe/Istanbul, 34854 Turkey. E-mail: nagihan_durmus@yahoo.com.

DOI: $10.4187 /$ respcare. 03883 
tion over the age of 15 smokes, corresponding to approximately 1.1 billion people worldwide, including 16 million people in Turkey. Without intervention, this number is estimated to rise to 1.7 billion worldwide by the year $2025 .{ }^{4}$ The biggest difficulty in reducing tobacco-related morbidity and mortality is convincing smokers to quit and maintain their abstinence. ${ }^{5}$ Epidemiological data show that $70 \%$ of smokers want to quit, and $46 \%$ of these have made a prior attempt to quit, abstaining for at least $1 \mathrm{~d} .6,7$

People who want to quit smoking need a facilitative support approach to achieve abstinence. This may include non-pharmacologic and pharmacologic support programs and sometimes both. Even with pharmacologic and supportive therapy, quitting smoking is difficult for most smokers, and a considerable number of attempts result in relapses. . $^{8-10}$

In Turkey, the number of applications to smoking cessation clinics by individuals who want to quit increases every day. This is due to social awareness, prohibition of smoking in closed environments, associated diseases, and economic reasons. This motivation to quit can be supported by various medical and behavioral therapies.7,11 Determining the risk factors associated with unsuccessful attempts to quit may help in providing a more conscious and effective support treatment. We aimed to determine the relapse rate after $1 \mathrm{y}$ and the factors affecting relapse in subjects who applied to a Smoking Cessation Clinic in our hospital.

\section{Methods}

\section{Study Design}

This was a case-control study. The control group comprised subjects who did not relapse. This study was approved by the local ethics committee.

\section{Setting}

This study was carried out in the Smoking Cessation Clinic of the Istanbul Süreyyapaşa Chest Diseases and Thoracic Surgery Education and Research Hospital. Istanbul is the most populous and leading commercial city in Turkey. It has a population of 14 million and has the most immigrants of any Turkish city.

\section{Subject Selection and Subject Characteristics}

Within the scope of the Smoking Cessation Program, the personal and social drawbacks of smoking were explained to all subjects as a group in their first meeting. The significance of making the decision to quit was highlighted, and subjects who made the decision were given cognitive and behavioral education on quitting. A quit date was

\section{QUICK LOOK}

\section{Current knowledge}

Despite increased awareness of smoking risks, this behavior continues to present a serious public health problem, constituting one of the most frequent preventable causes of morbidity and mortality. The most important difficulty for reduction of tobacco-related morbidity and mortality is to convince smokers to quit and maintain their abstinence. Epidemiological data have shown that $70 \%$ of smokers want to quit, and $46 \%$ have attempted to quit in the past, abstaining for at least 1 day. Even with pharmacotherapy and supportive therapy, quitting smoking is difficult for most smokers, and a considerable number of attempts result in relapses.

\section{What this paper contributes to our knowledge}

The relapse rate following smoking cessation in a 1-y period was $51 \%$. Alcohol intake presented a risk for relapse. In patients who receive drug treatment, planning controls more frequently and attention to adverse effects may increase the success rates in smoking cessation treatment.

designated for each subject. Psychological support and motivating meetings were recommended once within the first $15 \mathrm{~d}$ following the quit date, once every month for the next 3 months, and once every 3 months for the following 9 months. Subjects were initially called for a face-to-face meeting. Subjects who did not attend the support meeting were phoned by a polyclinic nurse. The first meeting was carried out face-to-face, and subsequent support contacts were made either face-to-face or by telephone contact. Face-to-face and telephone contacts were available for each subject. Subject follow-up in the Smoking Cessation Polyclinic was carried out by a pulmonary disease specialist doctor in our hospital; psychiatric consultation was given as required, and subjects were followed up together in selected cases.

A total of 550 subjects who participated in the smoking cessation program from June 1 to December 31, 2011 and who completed a 1-year follow-up were included in the study. The demographic characteristics of the subjects, Fagerström nicotine dependence scores, Beck depression scores, presence of respiratory symptoms, pulmonary function test results, concomitant diseases, age began smoking, number of smoking years, daily cigarette count, smoking behavior in their environment (family, friends, and workplace), conditions that increase smoking desire (after meals, tea, coffee, alcohol intake, friend circle, workplace, etc), presence of regular alcohol consumption (alcohol consumption is defined as having up to $1 \mathrm{drink} / \mathrm{d}$ ), reason for 
quitting (health, family, financial), prior attempts to quit (and, if any, how long they lasted), whether they received pharmacologic treatment in addition to psychological support for quitting, type of pharmacotherapy, presence of adverse effects and their type, number of support contacts during the 1-year follow-up period, and time of relapse in relapsed subjects were obtained from subject records and entered into the database.

At the end of the 1-y period, the subjects who quit smoking were grouped into the non-relapsed group, whereas those who started to smoke again at any time during the year were grouped in the relapsed group. Those subjects who did not attend any support visits and who were not contactable on 2 different occasions were grouped in the unknown smoking status group. Since there was no carbon monoxide measurement facility in our hospital, the subject's smoking status was self-reported.

\section{Statistics}

The dependent variable or outcome was a relapse. The independent variables (risk factors) were: age, sex, age began smoking, smoking years, daily smoking count, education level, motivation to quit in the past and the longest period of abstinence, reason to quit, exposure to environmental tobacco smoke, alcohol intake, Fagerström nicotine dependence score, Beck depression score, respiratory symptoms, pulmonary function test parameters, pharmacotherapy, presence of adverse effects, and number of support interviews.

Measures subject to statistical analysis in the study were defined as the mean, SD, frequency, and percentage values. The chi-square and Fisher's exact probability tests were used to compare frequency and percentages between the groups.

For a comparison of normally distributed continuous variables between the 2 groups (relapsing and non-relapsing), the $t$ test was used. When the distribution of variables was not normal, The Mann-Whitney $U$ test was used for comparison. Multiple backward stepwise logistic regression analyses were performed to detect any associations between variables and to express their mathematical model. A $P$ value of .05 was considered significant. Statistical analyses were carried out using SPSS 17.5 (SPSS, Chicago, Illinois).

\section{Results}

The age of the 550 subjects included in the study varied between 15 and 76 y (mean: $41.5 \pm 10.8$ y); 289 (52.5\%) were male, and $261(47.5 \%)$ were female. After $1 \mathrm{y}$, the number of relapsed subjects was $282(51.4 \%)$, the number of non-relapsed subjects was $132(24 \%)$, and
Table 1. Comparison of Relapsed and Non-Relapsed Subjects According to Quantitative Variables

\begin{tabular}{lccc}
\hline \hline \multicolumn{1}{c}{ Variables } & $\begin{array}{c}\text { Relapsed } \\
(n=291)\end{array}$ & $\begin{array}{c}\text { Non-Relapsed } \\
(n=132)\end{array}$ & $P$ \\
\hline Age, y & $41.7(11.3)$ & $42.4(9.3)$ & .52 \\
Age began smoking, y & $18.0(4.8)$ & $19.1(5.5)$ & .05 \\
Duration of smoking, y & $24.5(15.5)$ & $23.3(9.5)$ & .44 \\
Cigarette pack-years & $23.8(11.2)$ & $23.4(9.5)$ & .67 \\
FNDS & $5.7(2.5)$ & $5.6(2.4)$ & .96 \\
BDS & $11.3(8.1)$ & $11.9(8.8)$ & .43 \\
FVC, L & $3.4(1.0)$ & $3.3(1.0)$ & .52 \\
FVC, \% predicted & $85.7(15.8)$ & $86.3(15.0)$ & .69 \\
FEV ${ }_{1}$, L & $2.9(0.9)$ & $2.8(0.9)$ & .49 \\
FEV ${ }_{1}, \%$ predicted & $87.2(17.5)$ & $88.3(15.3)$ & .53 \\
FEV ${ }_{1} /$ FVC & $0.85(.088)$ & $0.858(.085)$ & .36 \\
No. of support contacts & $1.8(0.9)$ & $2.5(1.3)$ & $<.001$ \\
& & & \\
\hline Data are shown as mean (SD). & & & \\
Mann-W = Mann-Whitney $U$ test & & & \\
FNDS = Fagerström nicotine dependence score & & \\
BDS = Beck depression score & & & \\
\hline
\end{tabular}

the number of cases with unknown smoking status was $135(24.6 \%)$.

When the relapsed group was compared with the nonrelapsed group according to quantitative variables, the age began smoking $(P=.05)$ and number of support contacts $(P<.001)$ were found to be significantly higher in the non-relapsed group (Table 1). The number of support contacts after the quit date varied between 0 and 5 (median: $2.0 \pm 1.3)$. In the relapsed and non-relapsed groups, the average number of face-to-face meetings was $0.9 \pm 0.7$ and $1.2 \pm 0.9$, respectively $(P<.001)$. The average number of telephone interviews was $0.8 \pm 0.7$ in the relapsed group and $1.3 \pm 0.9$ in the non-relapsed group $(P=.02)$. There was a significant difference between the 2 groups with respect to alcohol intake $(P<.001)$ and the duration of abstinence in the past $(P=.04)$ (Table 2). There was no association between the presence of comorbidities and relapse state (the distribution of comorbidities is shown in Fig. 1).

Pharmacotherapy along with supportive treatment was administered in $470(85.4 \%)$ cases. The most frequently used agent for medical treatment was varenicline $(n=206$, $43.7 \%$ ), but there was no difference between drugs in terms of treatment success (Table 3). Although subjects with depression received all types of pharmacotherapy, the rate of varenicline use was lower than in the general group $(n=18,18.9 \%)$.

Drug-related adverse effects were observed in a total of $61(13 \%)$ subjects. The most common adverse effects were nausea $(22.9 \%)$, sleep disorders $(13.1 \%)$, skin reactions (11.4\%), depression (9.8\%), and gastrointestinal intoler- 
Table 2. Comparison of Relapsed and Non-Relapsed Group According to Categorical Variables

\begin{tabular}{|c|c|c|c|}
\hline Variables & $\begin{array}{l}\text { Relapsed, } \\
n(\%)\end{array}$ & $\begin{array}{c}\text { Non-relapsed, } \\
n(\%)\end{array}$ & $P$ \\
\hline \multicolumn{4}{|l|}{ Sex } \\
\hline Male & $159(56.4)$ & $62(47.0)$ & \multirow[t]{2}{*}{.07} \\
\hline Female & $123(43.6)$ & $70(53.0)$ & \\
\hline \multicolumn{4}{|l|}{ Cigarette count, daily } \\
\hline$\leq 10$ & $32(11.5)$ & $13(9.9)$ & \multirow[t]{4}{*}{.27} \\
\hline $11-20$ & $118(42.4)$ & $63(48.1)$ & \\
\hline $21-30$ & $97(34.9)$ & $35(26.7)$ & \\
\hline$>30$ & $31(11.2)$ & $20(15.3)$ & \\
\hline \multicolumn{4}{|c|}{ Environmental exposure } \\
\hline Home & $42(15.4)$ & $19(15.1)$ & \multirow[t]{4}{*}{.89} \\
\hline Work & $34(12.5)$ & $13(10.3)$ & \\
\hline Friends & $57(21.0)$ & $25(19.8)$ & \\
\hline All & $139(51.1)$ & $69(54.8)$ & \\
\hline \multicolumn{4}{|l|}{ Alcohol intake } \\
\hline Yes & $87(31.3)$ & $18(14.0)$ & \multirow[t]{2}{*}{$<.001$} \\
\hline No & $191(68.7)$ & $111(86.0)$ & \\
\hline \multicolumn{4}{|l|}{ Quitting attempts } \\
\hline Yes & $242(87.4)$ & $111(86.0)$ & \multirow[t]{2}{*}{.71} \\
\hline No & $35(12.6)$ & $18(14.0)$ & \\
\hline \multicolumn{4}{|l|}{ Duration of abstinence } \\
\hline$<1 \mathrm{mo}$ & $139(65.9)$ & $47(49.0)$ & \multirow[t]{4}{*}{.04} \\
\hline $1-6 \mathrm{mo}$ & $50(23.7)$ & $34(35.4)$ & \\
\hline $7-12 \mathrm{mo}$ & $12(5.7)$ & $7(7.3)$ & \\
\hline$>12 \mathrm{mo}$ & $10(4.7)$ & $8(8.3)$ & \\
\hline \multicolumn{4}{|l|}{ Education level } \\
\hline None & $5(1.8)$ & $1(0.8)$ & \multirow[t]{5}{*}{.88} \\
\hline Primary school & $70(25.2)$ & $33(25.2)$ & \\
\hline Secondary school & $34(12.2)$ & $14(10.7)$ & \\
\hline High school & $91(32.7)$ & $42(32.1)$ & \\
\hline University & $78(28.1)$ & $41(31.2)$ & \\
\hline \multicolumn{4}{|l|}{ Comorbidity } \\
\hline Yes & $122(43.3)$ & $57(43.2)$ & \multirow[t]{2}{*}{.98} \\
\hline No & $160(56.7)$ & $75(56.8)$ & \\
\hline \multicolumn{4}{|l|}{ Respiratory symptoms } \\
\hline Yes & $128(46.0)$ & $60(45.8)$ & \multirow[t]{2}{*}{.96} \\
\hline No & $150(54.0)$ & $71(54.2)$ & \\
\hline \multicolumn{4}{|l|}{ Pharmacotherapy } \\
\hline Yes & $258(91.5)$ & $119(90.2)$ & \multirow[t]{2}{*}{.66} \\
\hline No & $24(8.5)$ & $13(9.8)$ & \\
\hline
\end{tabular}

ance $(8.2 \%)$. The adverse effects observed and drugs administered are shown in Table 4.

Relapses occurred mostly in the first month (48.9\%) and during the first 6 months (37.8\%). According to the duration of pharmacotherapy, relapse rates were found to be higher around days 15-29 and days 60-90 of treatment (Fig. 2).

Variables (as shown in Table 5) (ie, alcohol intake and number of support contacts) were analyzed by multiple backward stepwise logistic regression and were found to have an important affect on relapse $(P=.02$ and $P<.001$,

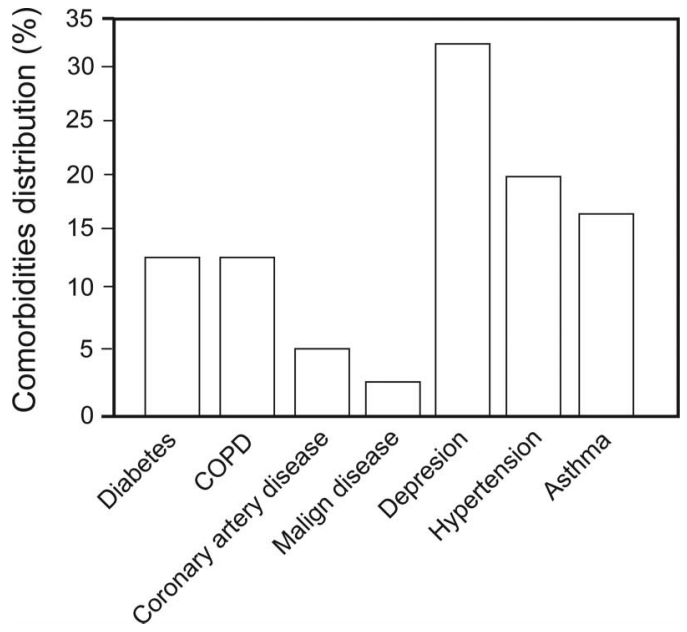

Fig. 1. Distribution of comorbidities: diabetes mellitus $(n=35$, $P=.68)$, COPD $(n=36, P=.33)$, coronary artery disease ( $n=14, P=.09)$, malign disease $(n=10, P=.94)$, depression ( $n=95, \quad P=.54)$, hypertension $(n=57, \quad P=.58)$, and asthma $(n=45, P=.14)$.

respectively). The presence of adverse effects was found to be close to significant $(P=.07)$.

\section{Discussion}

It is well known that $70 \%$ of smokers have a desire to quit, but $<10 \%$ can achieve abstinence for an extended period. ${ }^{7}$ In our study, we found no difference between the age, sex, educational status, daily cigarette count, environmental exposure to tobacco smoke, and nicotine dependence level of those subjects who returned to smoking at the end of $1 \mathrm{y}$ and those subjects who did not relapse. There are studies reporting diverse results on this subject. In 1 study that looked at demographic and smoking-related factors, being older, married, and male, having a lesser number of daily cigarettes, not being exposed to tobacco smoke at home, having a lower nicotine dependence level, having a longer prior abstinence period, and having a lower alcohol intake were found to be associated with a greater success of quitting. ${ }^{5}$ In another study, alcohol intake and environmental exposure to tobacco smoke were determined to be risk factors for relapse, whereas age, sex, and education level were found not to be associated with relapse. ${ }^{12}$ A further study involving 103 smokers found a difference in smoking behavior between the sexes and found that the relapse rate was higher in males at the end of 1 year. ${ }^{13}$ On the contrary, other studies have found male sex to be a protective factor against relapse. ${ }^{14,15}$ Japuntich et al ${ }^{16} \mathrm{em}$ phasized the significance of sex and the nicotine dependence level. In addition, several studies have noted the presence of another smoking person in the household environment as a factor affecting relapse. ${ }^{12,17-19}$ 
Table 3. Success Rates and Association With Relapse According to Type of Pharmacotherapy administered

\begin{tabular}{lcccr}
\hline \hline \multicolumn{1}{c}{ Agents $(n=470)$} & $n(\%)$ & Relapsed, $n$ & Non-Relapsed, $n$ & Treatment Success, $\%$ \\
\hline Varenicline & $206(43.7)$ & 112 & 94 & 45.6 \\
Bupropione & $137(29.0)$ & 67 & 70 & 51.1 \\
Nicotine patches & $100(21.2)$ & 48 & 52 & 52.0 \\
Nicotine gum & $12(2.5)$ & 10 & 2 & .79 \\
Bupropion + nicotine patches & $12(2.6)$ & 7 & 5 & .06 \\
Bupropion + nicotine gum & $2(0.4)$ & 1 & 1 & .16 \\
Varenicline + nicotine patches & $1(0.2)$ & 0 & 1 & .52 \\
\hline
\end{tabular}

Table 4. Adverse Effects Related to Drugs and Their Frequencies

\begin{tabular}{lcccc}
\hline \hline & \multicolumn{3}{c}{ Type of Drug } \\
\cline { 2 - 5 } Type of side effect $(n=61)$ & Varenicline, $n$ & Bupropion, $n$ & Nicotine patches, $n$ & 0 \\
Nausea & 13 & 0 & 1 & 1 \\
Sleep disorder & 5 & 2 & 0 & 0 \\
Abnormal dreaming & 4 & 0 & 7 & 0 \\
Skin reaction & 0 & 0 & 0 & 0 \\
Depression & 4 & 2 & 0 & 0 \\
Gastrointestinal intolerance & 3 & 2 & 0 & 0 \\
Skin rash & 2 & 2 & 0 & 0 \\
Anxiety & 3 & 0 & 0 & 0 \\
Headache & 2 & 1 & 0 \\
Tremor & 0 & 2 & 0 \\
Dryness at mouth & 1 & 1 & 0 \\
Hallucinations & 1 & 0 & 0 \\
\hline
\end{tabular}

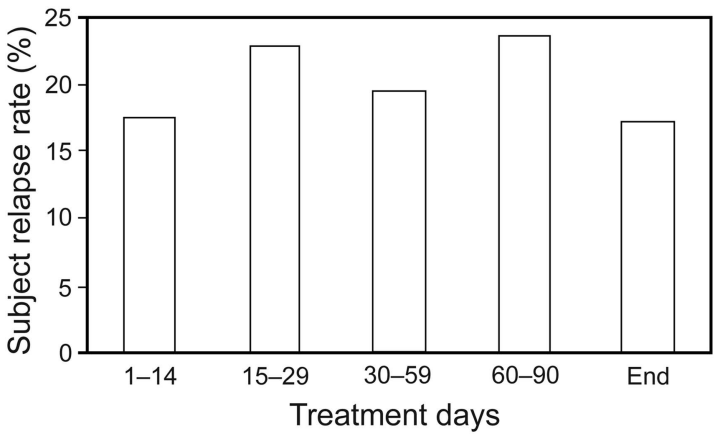

Fig. 2. Relapse rates according to the duration of pharmacotherapy.

Most adult smokers start smoking in their youth. Adolescents carry a greater risk for starting smoking and developing dependence, and the starting age for smoking is reported to be a determining factor for relapse. ${ }^{20,21}$ Studies carried out in Turkey indicate that the age began smoking varies between 13 and 20.,17,22-25 In our study, the age began smoking was significantly younger in the relapsed group compared with the non-relapsed group.

Among those subjects who attend smoking cessation programs, a certain percentage of these have attempted to quit several times in the past. 26,27 The presence and num-
Table 5. Multiple Backward Stepwise Logistic Regression Showing Variables With a Significant Effect on Relapse

\begin{tabular}{lccc}
\hline \hline Variables, step $10^{*}$ & $P$ & OR & $95 \% \mathrm{CI}$ \\
\hline Alcohol intake & .02 & 2.11 & $1.13-3.93$ \\
Number of controls & $<.001$ & 2.06 & $1.59-2.65$
\end{tabular}

* Variable(s) entered on step 1: alcohol intake (yes/no), environmental exposure (home/work/friends/all), reason to quit (health/family/financial), educational status

(none/primary school/secondary school/high school/university), respiratory symptoms (yes/no), Beck depression score, number of controls, pharmacotherapy (yes/no), side effects (yes/no). $\mathrm{OR}=$ odds ratio

ber of prior failed attempts is reported to be a significant adverse factor for subsequent attempts to quit. ${ }^{26}$ Our results supported this; the longest period of prior abstinence was significantly lower in the relapsed group.

Many studies indicate an association between alcohol intake and relapse. ${ }^{2,5,12,17}$ In our study, there was a significantly higher alcohol intake in the relapsed subjects $(31 \%$ vs $14 \%)$.

Another study showed that subjects who relapsed subsequent to quitting smoking after hospitalization for acute coronary syndrome had a higher level and intensity of depression. ${ }^{28}$ Similarly, in cancer subjects who quit smoking after surgical treatment, relapse was found to be asso- 
ciated with depression. ${ }^{29}$ In contrast, a study involving 677 subjects showed that, although a history of depression was found to be a determining factor for relapse in the short term, it was not significant in the long term. ${ }^{30}$ In our center, the Beck depression scale is used on each subject attending the smoking cessation program, and those with a high score and those who have a history of depression are referred to a psychiatric specialist, and the follow-up and treatment of these subjects are planned together. In our study, 95 (17.3\%) subjects were diagnosed with depression, and, of these, there was no difference in the mean Beck depression scores between the relapsed and nonrelapsed group. However, the information obtained with the Beck depression scale is subjective, and the number of subjects with depression in the whole group was small. Thus, it will be important to investigate the effect of depression on quitting smoking in a further study with a greater number of subjects suffering depression.

In our subject group, relapses were most remarkable within the first month (48.9\%) and then during the first 6 months (37.8\%). Similarly, other studies note relapses mostly during the first 6 months. ${ }^{18,31}$

Most smokers assume that all that is necessary to quit is the decision to do it, but this is reported to be a misconception. ${ }^{32}$ In addition to behavioral and motivational support, pharmacologic treatment is also recommended in selected subjects. In our study, subjects received behavioral and psychological supportive treatment, and $85.4 \%$ received pharmacotherapy, including varenicline, bupropion, nicotine replacement treatment, or a combination of these. Several studies report that prolonged treatment with varenicline may prevent relapse. ${ }^{5,29}$ Prolonged nicotine replacement treatment has shown promising but controversial results, ${ }^{5}$ as there are more relapses with short-term nicotine replacement treatment compared with treatment regimens including bupropion and varenicline. ${ }^{33}$ Interestingly, we found no difference in relapse rates between subjects who received pharmacologic treatment and those who did not. There was also no association between the type of pharmacotherapy and success of treatment, although the success rate with a nicotine patch alone was $52 \%$ (yielding a $P$ value close to significant). This finding may be due to the relatively low adverse effects of nicotine patches and their higher tolerability.

There was a $13 \%$ incidence of adverse effects in those cases who received pharmacotherapy in our study. The presence of adverse effects was noteworthy, as the $P$ value was close to significant after regression analysis, and it may be a factor affecting the success of pharmacotherapy indirectly. The reported adverse effects of varenicline, the most frequently prescribed agent used in our subjects, include the increased risk for cardiovascular accident development, ${ }^{34}$ nausea, ${ }^{35-38}$ abnormal dreaming, sleeplessness, ${ }^{36,38}$ headache, ${ }^{37,38}$ depression, and possible serious psychiatric conditions. ${ }^{39,40}$ The most frequent adverse effect we observed with varenicline was nausea. In addition, disrupted sleep, abnormal dreaming, depression, anxiety, gastrointestinal intolerance, skin rash, headache, hallucinations, and dryness of the mouth were also noted. Bupropion causes nausea, sleeplessness, anxiety, dryness of the mouth, and increased risk of seizures by decreasing the epileptic threshold. ${ }^{34}$ We noted adverse effects related to bupropion in 12 subjects, and these included depression, gastrointestinal intolerance, skin rashes, sleeplessness, tremors, headache, and dryness of the mouth. Adverse effects of nicotine replacement treatment are rare and mostly include skin reactions, irritation, and burning sensations in the mouth and throat. ${ }^{34,40}$ Skin reactions were seen in 7 of our subjects following nicotine patch use. Adverse effects of nicotine gum are reported to be gastrointestinal intolerance and nausea, and these were observed in only 3 of our subjects. Consistent with the literature, the most commonly observed adverse effects in our subject group were nausea, sleep disorders, abnormal dreaming, skin reactions, depression, and gastrointestinal adverse effects.

Since sleep disorders and midnight awakenings are also symptoms of nicotine withdrawal, they were investigated in a Greek study ${ }^{41}$ and were found to be independent variables associated with relapse. Also, the use of bupropion and smoking the first cigarette of the day $30 \mathrm{~min}$ after getting up has been shown to increase quitting success. ${ }^{41}$ Since our study was not a prospective one, we could only analyze the variables that had been recorded, and nicotine withdrawal symptoms could not be analyzed in our study. As it is observed, sleep disorders should be examined from both perspectives. Pharmacotherapy did not have a significant effect on success in our study. Although the study design of Boutou et $\mathrm{al}^{41}$ was prospective, in our opinion, it would be improper to draw a conclusion from the longterm results, since the follow-up time was only 6 months.

We showed that the average number of support meetings in $1 \mathrm{y}$ in subjects who were followed up in the polyclinic after quitting was significantly higher in the nonrelapsed versus the relapsed subjects. The chance of intervening in the event of adverse effects is more likely in those subjects who attend support visits more regularly, and this factor may have affected this result.

There are some limitations to our study. The primary limitation is the subjective, self-reported evaluation of the subject's smoking status due to the lack of ability to measure carbon monoxide in exhaled breath in our hospital. Also, there was a high number of subjects who could not be contacted during follow-up and whose smoking status was unknown, as the study was not planned as a prospective design. In our polyclinic, the first interview with the subject is face-to-face, and subsequent communications are preferably face-to-face, but if not, they are via telephone contact. Each subject was assigned support meet- 
ings both face-to-face and via telephone contact, and the total number of communications was reported as the number of support meetings. Different ways of conducting these support contacts may have an influence on success rates.

In addition, analysis of nicotine withdrawal symptoms, such as weight gain, which could influence relapse, could not be performed, since data analysis was retrospective, and this information was not available. A prospective study including different parameters that may affect relapse is necessary to take account the many variables that may influence a relapse during this complicated time.

There is also the question as to what extent our results can be generalized. Certainly, the behavior of smokers is expected to differ around the world and even within Turkey. At this point, it should be noted that Istanbul is the most cosmopolitan city in Turkey, and our hospital is one of the most important reference centers for pulmonary diseases in the country. On the other hand, our results are remarkable in that they emphasize the close follow-up of a specific subject group in whom the success rate is not high, despite various treatment methods that are commonly administered today.

\section{Conclusions}

The relapse rate at the end of $1 \mathrm{y}$ was $51.4 \%$ in our smoking cessation center. In accordance with previous studies, alcohol intake presents a risk for relapse. The relapse rate did not differ in those subjects receiving pharmacotherapy; however, the presence of adverse effects from these agents was thought to be notable for relapse. Planning more frequent support contacts for subjects receiving medical treatment and paying attention to the development of adverse effects may increase success rates in smoking cessation programs.

\section{REFERENCES}

1. Hand S, Edwards S, Campbell IA, Cannings R. Controlled trial of three weeks nicotine replacement treatment in hospital patients also given advice and support. Thorax 2002;57(8):715-718.

2. VanderVeen JW, Gulliver SB, Morissette SB, Kruse MI, Kamholz $\mathrm{BW}$, Zimering RT, et al. Differences in drinking patterns, occupational stress, and exposure to potentially traumatic events among firefighters: predictors of smoking relapse. Am J Addict 2012;21(6): 550-554.

3. Bilgiç N, Günay T. A method for supporting smoking cessation in adolescents: peer education. Turk Thorac J 2014;115(3):102-105.

4. Özyurt BC. Smoking prevalence among Celal Bayar University Faculty of Medicine. Eurasian J Pulmonol 2009;11(3):93-96.

5. Heffner JL, Lee TC, Arteaga C, Anthenelli RM. Predictors of posttreatment relapse to smoking in successful quitters: pooled data from two phase III varenicline trials. Drug Alcohol Depend 2010;109(1): 120-125.

6. Smith SS, Jorenby DE, Fiore MC, Anderson JE, Mielke MM, Beach $\mathrm{KE}$, et al. Strike while iron is hot: can stepped-care treatments res- urrect relapsing smokers. J Consult Clin Psychol 2001;69(3):429439.

7. Solak ZA, Telli CG, Erdinç E. Results of smoking cessation program. Turk Toraks Derg 2003;4(1):73-77.

8. Lancaster T, Hajek P, Stead LF, West R, Jarvis MJ. Prevention of relapse after quitting smoking: a systematic review of trials. Arch Intern Med 2006;166(8):828-835.

9. Yong HH, Borland R, Cooper JC, Cummings KM. Postquitting experiences and expectations of adult smokers and their association with subsequent relapse: findings from the International Tobacco Control (ITC) Four Country Survey. Nicotine Tob Res 2010; 12(Suppl):iii12-iii19.

10. Hajek P, Stead LF, West R, Jarvis M, Lancaster T. Relapse prevention interventions for smoking cessation. Cochrane Database Syst Rev 2013;(8):CD003999. doi: 10.1002/14651858.CD003999.pub4

11. Argüder E, Karalezli A, Hezer H, Kılıç H, Er M, Hasanoğlu HC, et al. Factors affecting the success of smoking cessation. Turk Toraks Derg 2013;14(3)81-87.

12. Garvey AJ, Bliss RE, Hitchcock JL, Heinold JW, Rosner B. Predictors of smoking relapse among self-quitters: a report from the Normative Aging Study. Addict Behav 1992;17(4):367-377.

13. Nieva G, Valero S, Bruguera E, Andión Ó, Trasovares MV, Gual A, Casas M. The alternative five-factor model of personality, nicotine dependence and relapse after treatment for smoking cessation. Addict Behav 2011;36(10):965-971.

14. Borrelli B, Papandonatos G, Spring B, Hitsman B, Niaura R. Experimenter-defined quit dates for smoking cessation: adherence improves outcomes for women but not for men. Addiction 2004;99(3):378385 .

15. Wetter DW, Kenford SL, Smith SS, Fiore MC, Jorenby DE, Baker TB. Gender differences in smoking cessation. J Consult Clin Psychol 1999;67(4):555-562.

16. Japuntich SJ, Leventhal AM, Piper ME, Bolt DM, Roberts LJ, Fiore MC, Baker TB. Smoker characteristics and smoking-cessation milestones. Am J Prev Med 2011;40(3):286-294.

17. Göksel T, Cirit M, Bayındır Ü. Factors affecting smoking behavior in high school students in Izmir. Turk Toraks Derg 2001;2(3):49-53.

18. Polanska K, Hanke W, Sobala W, Lowe JB, Jaakkola JJ. Predictors of smoking relapse after delivery: prospective study in central Poland. Matern Child Health J 2011;15(5):579-586.

19. Macy JT, Seo DC, Chassin L, Presson CC, Sherman SJ. Prospective predictors of long-term abstinence versus relapse among smokers who quit as young adults. Am J Public Health 2007;97(8):14701475.

20. Flores Mateo G, Morchón Ramos S, Masuet Aumatell C, Carrillo Santisteve P, Manchón Walsh P, Ramon Torrell JM. Age of smoking initiation as predictor in smoking cessation. Aten Primaria 2005; 35(9):466-471.

21. Hurt RD, Wolter TD, Rigotti N, Hays JT, Niaura R, Durcan MJ, et al. Bupropion for pharmacologic relapse prevention to smoking: predictors of outcome. Addict Behav 2002;27(4):493-507.

22. Karlıkaya C. Smoking prevalence among high school students in Edirne: smuggling, advertising and adolescence access to cigarettes. Turk Toraks Derg 2002;3(1):7-12.

23. Arbak P, Erdem F, Karacan Ö, Özdemir Ö. Smoking habits in high school students in Düzce. Eurasian J Pulmonol 2000;2(1):17-21.

24. Turgut T, Deveci F, Altuntaş E, Muz MH. The results of the cigarette questionnaire applied to the teachers of high school in Elazı $\breve{g}$. Eurasian J Pulmonol 2001;3(4):295-299.

25. Coşkun F, Karadağ M, Ursavaș A, Ege E. Smoking habits of the teachers and their opinion about the new law. Eurasian J Pulmonol 2012;12(3):119-124.

26. Partos TR, Borland R, Yong HH, Hyland A, Cummings KM. The quitting rollercoaster: how recent quitting history affects future ces- 


\section{Relapse Factors in a Smoking Cessation Program}

sation outcomes (data from the International Tobacco Control 4-country cohort study). Nicotine Tob Res 2013;15(9):1578-1587.

27. Borland R, Partos TR, Yong HH, Cummings KM, Hyland A. How much unsuccessful quitting activity is going on among adult smokers? Data from the International Tobacco Control Four Country cohort survey. Addiction 2012;107(3):673-682.

28. Perez GH, Nicolau JC, Romano BW, Laranjeira R. Depression: a predictor of smoking relapse in a 6-month follow-up after hospitalization for acute coronary syndrome. Eur J Cardiovasc Prev Rehabil 2008;15(1):89-94.

29. Simmons VN, Litvin EB, Jacobsen PB, Patel RD, McCaffrey JC, Oliver JA, et al. Predictors of smoking relapse in patients with thoracic cancer or head and neck cancer. Cancer 2013;119(7):14201427.

30. Japuntich SJ, Smith SS, Jorenby DE, Piper ME, Fiore MC, Baker TB. Depression predicts smoking early but not late in a quit attempt. Nicotine Tob Res 2007;9(6):677-686.

31. Snuggs S, McRobbie H, Myers K, Schmocker F, Goddard J, Hajek $\mathrm{P}$. Using text messaging to prevent relapse to smoking: intervention development, practicability and client reactions. Addiction 2012; 107(Suppl 2):39-44.

32. Borland R, Yong HH, Balmford J, Cooper J, Cummings KM, O'Connor RJ, et al. Motivational factors predict quit attempts but not maintenance of smoking cessation: findings from the International Tobacco Control Four country Project. Nicotine Tob Res 2010; 12(Suppl):S4-S11.

33. Coleman T, Agboola S, Leonardi-Bee J, Taylor M, McEwen A, McNeill A. Relapse prevention in UK Stop Smoking Services: cur- rent practice, systematic reviews of effectiveness and cost-effectiveness analysis. Health Technol Assess 2010;14(49):1-152.

34. Jain R, Majumder P, Gupta T. Pharmacological intervention of nicotine dependence. Biomed Res Int 2013;2013:278392. doi: $10.1155 /$ biomedresint.

35. Gibbons RD, Mann JJ. Varenicline, smoking cessation, and neuropsychiatric adverse events. Am J Psychiatry 2013;170(12):1460-1467.

36. Cui Q, Robinson L, Elston D, Smaill F, Cohen J, Quan C, et al. Safety and tolerability of varenicline tartrate for smoking cessation in HIV-infected subjects: a pilot open-label study. AIDS Patient Care STDS 2012;26(1):12-19.

37. Nakamura M, Oshima A, Fujimoto Y, Maruyama N, Ishibashi T, Reeves KR. Efficacy and tolerability of varenicline, an alpha4beta2 nicotinic acetylcholine receptor partial agonist, in a 12-week, randomized, placebo-controlled, dose-response study with 40-week follow-up for smoking cessation in Japanese smokers. Clin Ther 2007; 29(6): 1040-1056.

38. Jiloha RC. Pharmacotherapy of smoking cessation. Indian J Psychiatry 2014;56(1):87-95.

39. Cahill K, Stead LF, Lancaster T. Nicotine receptor partial agonists for smoking cessation. Cochrane Database Syst Rev 2012;(4): CD006103. doi: 10.1002/14651858.CD006103.pub6.

40. Hays JT, Ebbert JO. Adverse effects and tolerability of medications for the treatment of tobacco use and dependence. Drugs 2010;70(18): 2357-2372.

41. Boutou AK, Tsiata EA, Pataka A, Kontou PK, Pitsiou GG, Argyropoulou P. Smoking cessation in clinical practice: predictors of sixmonth continuous abstinence in a sample of Greek smokers. Prim Care Respir J 2008;17(1):32-38. 